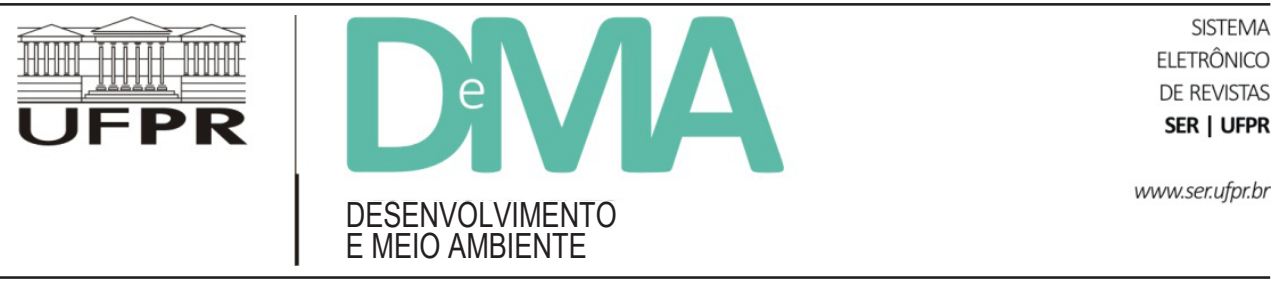

\title{
Bem-estar animal na produção de ovos orgânicos no Estado de São Paulo: percepção social e avaliação técnica nas granjas
}

\section{Animal Welfare in the Production of Organic Eggs in São Paulo State: Social Perception and Technical Evaluation of the Poultry Farms}

\author{
Fabiola Fernandes SCHWARTZ ${ }^{*}$, Lucimar Santiago de ABREU ${ }^{2}$ \\ ${ }^{1}$ SFS Boas Práticas Agropecuárias e Traduções Técnicas Ltda., Rio Claro, SP, Brasil. \\ ${ }^{2}$ Empresa Brasileira de Pesquisa Agropecuária (Embrapa Meio Ambiente), Jaguariúna, SP, Brasil. \\ *E-mail de contato: sfs.agroecologia@gmail.com
}

Artigo recebido em 4 de novembro de 2014, versão final aceita em 9 de novembro de 2015.

RESUMO: Neste artigo é apresentada a percepção de empresários rurais, gerentes, técnicos do setor agropecuário e trabalhadores de granjas sobre bem-estar animal (BEA) na produção de ovos orgânicos no Estado de São Paulo. As condições técnicas nas granjas foram avaliadas por meio de requisitos baseados em protocolos voltados ao bem-estar animal (Laywel, Welfare Quality ${ }^{\circledR}$, Globalgap) e em normas para produção orgânica (Instrução Normativa 46/2011 do Ministério da Agricultura, Pecuária e Abastecimento). Por meio de 21 entrevistas semiestruturadas, avaliou-se a percepção dos atores do processo produtivo em relação ao nível de informação e as dificuldades encontradas em relação ao tema BEA. O cruzamento das informações geradas pelas entrevistas e pela avaliação nas granjas evidenciou lacunas técnicas existentes no manejo orgânico e na implementação de práticas que promovam o BEA. Quanto ao conceito de BEA, todos os agentes consideram a questão relevante, dentro de seus universos próprios de compreensão e valores ético, sanitário e econômico. Nas granjas com mais de 10.000 aves, classificadas como agroindústrias de pequeno e médio portes, as condições de BEA são satisfatórias, respaldadas por assistência técnica, boas instalações e condições financeiras para investimentos. As granjas com um número inferior de aves apresentaram deficiência de infraestrutura e manejo, limitações financeiras e carência de assistência técnica, incorrendo em riscos para o BEA. Observa-se que a consonância entre o discurso dos agentes e as práticas efetivas de BEA está diretamente associada ao conhecimento sobre o tema. Onde há lacunas nesse conhecimento, não há o entendimento ou o dimensionamento dos impactos sobre o BEA, das deficiências sanitárias, nutricionais e de ambiência. Propõe-se o treinamento dos agentes sobre conceitos e práticas que contemplem o BEA em toda a sua abrangência ética, sanitária e econômica, para que as soluções e as adequações para os problemas possam ser discutidas e implementadas sobre bases sólidas de conhecimento.

Palavras-chave: bem-estar animal; avicultura orgânica; entrevista; capital humano. 
ABSTRACT: This paper deals with the perception of animal welfare (AW) on the part of rural entrepreneurs, agriculture/ cattle raising technicians and poultry farm workers in organic egg production in the state of São Paulo. The technical conditions at the poultry farms were assessed through the requirements based on protocols oriented towards animal welfare (Laywel, Welfare Quality ${ }^{\circledR}$, Globalgap) and organic production standards (Regulatory Instruction 46/2011/Ministry of Agriculture, Cattle-Raising and Supply). Through 21 semi-structured interviews, the perception and level of information on the subject, as well as the difficulties found by the production process agents, were assessed. By crossing information gathered at the interviews and from AW evaluation at poultry farms, some technical gaps in organic handling and implementation of AW-enhancing practices were found. Regarding the AW concept, all agents find it relevant within their own universe of comprehension and ethical, sanitary and economic values. At poultry farms with over 10.000 hens, the AW conditions are satisfactory, supported by technical assistance, good facilities and financial conditions for investment. Poultry farms with a lower number of hens, on the other hand, show poor infrastructure and handling, face financial limitations and lack technical assistance, thereby putting AW at risk. It can be seen that the consistency between the agents' views and actual AW practices is directly linked to knowledge of the subject. Where there are gaps in this knowledge, the impact on AW and sanitary, nutritional and environmental weaknesses cannot be recognized or measured. Guidance is proposed for these production sector agents on concepts and practices capable of covering the full ethical, sanitary and economic scope of AW, so that the solutions and adjustments for AW problems can be discussed and implemented on sound knowledge basis.

Keywords: animal welfare; organic aviculture; interview; human assets.

\section{Introdução}

É crescente a demanda por alimentos produzidos sob manejo orgânico, um crescimento anual de $20 \%$ a $30 \%$ do mercado mundial e brasileiro (Abreu et al., 2009), sendo que os consumidores que optam por estes produtos têm expectativa de que os animais tenham sido criados dentro de alto grau de bem-estar animal. E, nas últimas três décadas, as práticas de produção animal, seus impactos ambientais, a segurança de alimentos e a saúde humana e animal têm recebido crescente importância nos debates científicos, políticos e públicos sobre desenvolvimento sustentável; no entanto, temas sobre as relações ser humano-animal implicadas no bem-estar animal pouco têm sido discutidas em termos sociológicos (Geoff \& Vicky, 2014).

Os protocolos de produção orgânica, em sua maioria, preconizam a consideração de questões de BEA (IFOAM, 2005; CEE, 2007; Brasil, 2011). A Instrução Normativa 46, de 2011, do Ministério da Agricultura, Pecuária e Abastecimento (Brasil, 2011), apresenta os seguintes requisitos:

\section{Seção III}

Do Bem-Estar Animal

Art. 25. Os sistemas orgânicos de produção animal devem ser planejados de forma que sejam produtivos e respeitem as necessidades e o bem-estar dos animais. Art. 26. Deve-se dar preferência por animais de raças adaptadas às condições climáticas e ao tipo do manejo empregado.

Art. 27. Devem ser respeitadas:

I - a liberdade nutricional: os animais devem estar livres de sede, fome e desnutrição;

II - a liberdade sanitária: os animais devem estar livres de feridas e enfermidades;

$[\ldots]$

Assim, a avaliação da percepção social dos agentes envolvidos no processo produtivo é importante à medida que, segundo Rahmann (2003) e Abreu (2006), a discussão sobre BEA deveria considerar as práticas usadas no manejo, as funções, os valores éticos e as percepções dos atores envolvidos no processo de criação animal. São as posturas sociais adotadas na rotina diária nas granjas que expressam a interação entre o humano e o animal e que impactam diretamente a implementação, a manutenção e a eficiência dos procedimentos de BEA no manejo produtivo (Alencar et al., 2007) e também no desenvolvimento das aves (Hemsworth, 1994; Jensen, 2013).

Assim, buscou-se identificar as carências e as lacunas do processo de produção de ovos orgânicos, bem como analisar a coerência entre o discurso e as práticas referentes ao BEA. O diagnóstico de discrepâncias e 
suas causas poderá auxiliar futuros direcionamentos de pesquisas, a estruturação de treinamentos de agentes e a fundamentação de legislação sobre BEA.

\section{Materiais e métodos}

\subsection{Entrevistas semiestruturadas}

A pesquisa foi realizada por meio da aplicação de entrevistas semiestruturadas, buscando compreender o sentido dos conteúdos dos discursos dos atores-chave do processo de produção, buscando identificar e qualificar a pertinência entre discursos e práticas concretas adotadas na gestão do manejo das aves. Este tipo de entrevista é indicado para investigar aspectos afetivos e o sistema de valores dos entrevistados, raízes de suas atitudes e comportamentos (Selltiz et al., 1987 apud Boni \& Quaresma, 2005)ํ. Portanto, foram construídos questionários com perguntas abertas ou semiestruturadas para cada uma das categorias de agentes participantes do processo produtivo: empresário rural (portes pequeno, médio e grande), gerente, técnico do setor agropecuário e trabalhador das granjas. As entrevistas foram realizadas pessoalmente nas granjas e gravadas para posterior transcrição e análise ${ }^{2}$. Algumas das principais perguntas elaboradas estão discriminadas abaixo:

a) Poderia nos contar sobre sua experiência de trabalho na agricultura?; b) Fale do seu conhecimento sobre agricultura orgânica?; E sobre a Agroecologia?; c) O Sr. realizou cursos ou algum tipo de treinamento, ou recebeu alguma informação sobre este tipo de produção?; d) Como e por que optou pela produção orgânica?; e) Na sua opinião, quais são as vantagens ou facilidades e desvantagens ou dificuldades da produção orgânica?; f) Quais os maiores problemas enfrentados no seu sistema de produção?; g) Onde o senhor busca soluções para os problemas enfrentados?; h) Qual a origem da alimentação dos animais?; i) O senhor já ouviu falar do BEA?; j) Qual é sua opinião sobre o BEA?; k) É viável em termos de rotina de trabalho? E em termos de custo financeiro?; 1) Quais são os problemas de saúde ou de comportamento que os animais apresentam, nesta granja?

Nos meses de fevereiro e março de 2012 foram visitadas oito (8) granjas, classificadas em dois perfis socioeconômicos: empresário rural de pequeno porte (4) e agroindústria de médio porte (4). Foram realizadas entrevistas com empresários de pequeno porte (ou familiar/ somente 02 empregados/CLT), empresário médio e de grande porte, trabalhador/gerente (8), trabalhadores de granjas (9) e com técnicos de nível superior que trabalhavam diretamente nas empresas ou eram prestadores de serviço (4). Ver categorias na Tabela 1.

\subsection{Método de análise das entrevistas e da situação concreta}

Optou-se por uma abordagem compreensiva e qualitativa das entrevistas (Abreu, 2006), articuladas com as observações concretas dos comportamentos dos agentes e do funcionamento das granjas.

Em relação aos empreendimentos, foram classificados de acordo com as seguintes características: 1) Número de aves alojadas (considerou-se empreendimento ou empresa de pequeno porte até 2.000 aves alojadas); 2) Tipo de gestão: familiar (no caso, é formada principalmente por neorrurais ${ }^{3}$ ) ou empresarial, sendo familiar a que utiliza mão de obra familiar ou a contratação de até dois funcionários em tempo integral, segundo o Programa Nacional de Agricultura Familiar (SEBRAE, 2011); 3) Número de funcionários; 4) Serviço de assistência técnica e/ou responsável técnico (se possui ou não possui); 5) Capacidade para investimentos (se possui ou não possui; de acordo com o relato dos entrevistados).

\footnotetext{
${ }^{1}$ SELLTIZ, C. et al. Métodos de pesquisa nas relações sociais. Tradução de Maria Martha Hubner de Oliveira. 2. ed. São Paulo: EPU, 1987. 2 O projeto de pesquisa foi aprovado pelo Comitê de Ética em Pesquisa em Seres Humanos da Universidade Federal de São Carlos, sob Parecer $\mathrm{N}^{\mathrm{o}} 239 / 2012$.

${ }^{3}$ A partir de meados dos anos 80, observa-se uma nova população no meio rural brasileiro, a exemplo do que já ocorria há mais tempo nos países desenvolvidos. Constituída por jovens, oriundos das cidades com conhecimento formal mais elevado (agrônomos, biólogos, advogados), que buscam melhoria de sua qualidade de vida e investem em atividades agropecuárias (Dias \& Mazetto, 2014).
} 
Como base para a avaliação e classificação das diferentes percepções e comportamentos concretos, adotou-se como referência os conceitos de Duncan (2005) e Broom (2011): os aspectos éticos do BEA, considerando, por exemplo, a senciência dos animais e a questão sanitária do processo de criação, considerando os impactos de más condições do BEA sobre a saúde animal e humana; a segurança dos alimentos, considerando a relação entre boas e más condições de BEA e a produtividade ou a natureza qualitativa e quantitativa na produção, além de sanções comerciais e a dimensão econômica.

Assim, a avaliação do conhecimento sobre BEA e do discurso dos agentes foi efetuada adotando uma abordagem que focaliza a complementaridade da estrutura e funcionamento prático do sistema de produção em granjas orgânicas no Estado de São Paulo e a percepção dos atores diretamente envolvidos, por meio da observação do comportamento dos indivíduos em situações estruturadas. Ou seja, há uma confrontação da realidade concreta com o conteúdo das entrevistas.

Subjacente a esta confrontação de informações, está implícita a diferenciação entre o que as pessoas fazem e o que elas dizem. Procedimentos de pesquisas que evitam separações artificiais entre a observação do comportamento concreto e a análise das percepções e representações sociais. Esta pesquisa adota a perspectiva de combinar a análise da estrutura e de processos sociais, neste caso aplicada à análise de problemas relativos à manipulação de regras, por meio de estudos de casos. Incluem uma ênfase na observação das discrepâncias existentes em relação à norma ou regras como parte da análise, bem como diferenciação entre normas e valores ideais, de um lado, e o comportamento concreto, de outro.

Neste estudo de caso, foi fundamental apoiar-se no repertório técnico e conceitual sobre BEA, para apreender a fluência e o conhecimento sobre esse conjunto de práticas e normas (BEA).

\subsection{Avaliação do BEA nas granjas produtoras}

O diagnóstico das condições do BEA nas granjas teve o objetivo de identificar e compreender suas per- cepções e atitudes em relação a normas preconizadas, confrontando o discurso dos agentes com as práticas efetivamente implementadas visando atender o BEA. As aves e o manejo nas granjas foram avaliados por requisitos baseados em protocolos de BEA e produção orgânica, a saber: Welfare Quality ${ }^{\circledR}$ (2009), Laywel, (2006), Globalgap (2012) e Instrução Normativa 46, MAPA, Brasil (2011).

Kjaer et al. (2011), revisando o método proposto por Tauson et al. (2005), sugeriram uma versão reduzida do método proposto no Laywel (2006) com duas mudanças: 1) Avaliar quatro partes do corpo (pescoço, dorso, asa e cauda); e 2) Avaliar os animais no chão, sem a apanha e o manuseio. Concluíram que esta versão simplificada, à semelhança do proposto por Bright et al. (2007), é um método fidedigno para avaliação das condições das aves, causando-lhes menos estresse que o método original. Assim, para a caracterização das condições de BEA das granjas, foram tomados os seguintes índices: 1) Ambiência, manejo e infraestrutura; 2) Empenamento; e 3) Sanidade.

O cumprimento, de forma satisfatória ou não, dos diferentes requisitos referentes à infraestrutura, ambiência e manejo foi pontuado por um (1) ou zero (0) (cumpre, não cumpre, respectivamente), sendo alguns requisitos graduados entre zero (0) e dois (2), sendo (0) ruim, (1) mediano, (2) satisfatório, calculando-se a porcentagem de atendimento aos requisitos, conforme método do protocolo Globalgap (2012). Ainda conforme esse protocolo, há requisitos que foram classificados como "maiores", por contemplarem as cinco liberdades (FAWC, 1993), portanto, considerados com grande potencial de impacto sobre o BEA, a saber: a área disponível às aves no galpão e para pastejo, os espaços em comedouros e bebedouros, a disponibilidade de ninhos, qualidade da água e de alimentos, da cama e do ar, bem como a temperatura ambiente, a porcentagem de mortalidade, o canibalismo e a opção por debicagem. Os demais requisitos foram denominados "menores": qualidade da cama dos ninhos, disponibilidade de poleiros, manejo de luz, saídas para solário, vulnerabilidade a predadores, controle de roedores, opção por muda forçada. A classificação segundo a porcentagem de atendimento aos requisitos foi definida como "satisfatória", considerando-se o cumprimento de 81,5 a $100 \%$ dos requisitos (referentes 
aos requisitos maiores); como "regular", cumprimento de 62,5 a $81,4 \%$ (referente aos requisitos menores) e de 0 a $62,4 \%$ como "insatisfatório".

A avaliação do empenamento das aves baseou-se na classificação de um (1) a quatro (4) (sendo 1 ruim, 4 satisfatório), com a somatória dos escores das diferentes partes do corpo expressando as condições das aves, sendo o escore mínimo (4) e o máximo (16). As imagens das lesões e empenamento dos diferentes escores são apresentadas por Tauson et al. (2005). Segundo o protocolo Laywel (2006), a partir de $30 \%$ do lote apresentando escore abaixo de 12, deve-se intervir e averiguar as causas do distúrbio; desta forma, considerou-se como insatisfatórias as condições dos lotes que apresentavam alterações iguais ou superiores a 30\%.

Os demais requisitos clínico-sanitários, lesões de pele, diarreia e infestações por piolhos foram classificados segundo os parâmetros discriminados na Tabela 2. Também em relação aos requisitos clínico-sanitários foram consideradas como insatisfatórias as condições dos lotes que apresentavam alterações iguais ou superiores a $30 \%$. Para a avaliação das condições físicas e clínicas das aves, percorreu-se o aviário duas vezes em sua extensão, avaliando os animais entre $3 \%$ a $5 \%$ do lote.

Para análise comportamental das aves, segundo o protocolo Laywel (2006), deve-se caminhar pelo aviário, parar por cinco minutos, por três vezes, em locais diferentes e observar a reação das aves. Classificou-se a índole do lote como: (0) fuga, (1) animais ariscos e desconfiados (zona de fuga até 1 metro) e (2) aproximação.

\section{Resultados e discussão}

Com base nas entrevistas de campo e nas visitas às granjas de produção, foram caracterizados dois grupos distintos de produtores: 1) Empresa ou agroindústria de médio porte, com assistência técnica e com média a grande capacidade de investimento; e 2) Pequeno ou médio empresário rural, com ou sem assistência técnica ou responsável técnico e baixa capacidade de investimento. Na Tabela 1, foram discriminados os perfis das granjas avaliadas.

No grupo 1, as granjas 7 e 8 fizeram a opção comercial da produção orgânica nos mercados interno e internacional, que se encontram em franco crescimento.
No caso das outras duas empresas, classificadas também dentro do grupo 1 (granjas 5 e 6), a opção por produzir de forma orgânica foi uma escolha que ocorreu já no início da atividade.

As empresas do grupo 2 pertenciam a pequenos empresários rurais que não têm na unidade de produção rural a sua única fonte de renda. A opção pela produção orgânica deveu-se ao valor agregado de seus produtos e ao mercado em expansão. No entanto, a opção por permanecer no setor de orgânicos parece estar mais associada a uma filosofia de vida, uma vez que relataram trabalharem, algumas vezes, com prejuízo.

\subsection{Resultados das entrevistas}

Quanto ao conceito de bem-estar animal e sua efetiva implementação, de maneira geral, todos consideraram a questão relevante, dentro de seus universos próprios de compreensão, valores e prioridades, quer sejam éticos, sanitários e/ou econômicos. Os empresários e técnicos do grupo 1 conhecem o conceito, a abrangência e as proposições do movimento de BEA e suas implicações legais e comerciais, como, por exemplo, a demanda da União Europeia.

No entanto, alguns se pautam exclusivamente por experiências adquiridas com a produção desenvolvida com a aplicação dos requisitos das normas de orgânicos, por exemplo, em questões relativas ao impacto da debicagem para o animal (Kuenzel, 2007; FAWC, 2007) e à importância do sombreamento, manejo e rodízio de pastagens (Guelber, 2005; Knierim, 2006; Zeltner, 2008).

Nas granjas do grupo 1, embora manifestassem respeito ao animal como ser senciente, a visão geral era de que os animais tinham de estar saudáveis, devido ao impacto econômico negativo que uma eventual enfermidade poderia acarretar à produtividade e à sobrevivência das aves. Ainda nas granjas do grupo 1, apresentava-se uma percepção associada às implicações comerciais do BEA, além dos impactos favoráveis sobre a produtividade. Duas granjas (5 e 8) possuíam certificação específica para BEA, pois acreditavam no seu potencial de agregar valor à imagem institucional da empresa e de facilitar a abertura de comércio no exterior. 
Em empresas nas quais a opção pela produção orgânica tinha um cunho primordialmente filosófico (5 e 6), percebia-se melhor embasamento técnico para a implementação e o exercício do BEA. Segundo relato de seus gerentes técnicos, quando essas empresas iniciaram suas atividades, há 20 anos, elas se apoiavam fundamentalmente no melhor equilíbrio fisiológico e consequente resistência a doenças que o BEA propicia, uma vez que os recursos e pesquisas para tratamentos alternativos ainda eram bastante escassos.

O conceito formal de BEA é desconhecido por trabalhadores dos grupos 1 e 2: esses apresentam uma postura de bondade e respeito pelas aves, oriundo provavelmente da experiência de convívio na infância com as produções de aves por seus familiares, mas desconheciam o que preconizam os princípios do BEA.

Os empresários do grupo 2 demonstram ter respeito pelas aves, considerando-as como seres sencientes, que precisam ser bem tratadas para se manterem saudáveis e produzindo bem; mas não conheciam claramente a abrangência técnica, prática, legal e comercial do movimento pró-BEA.

Diante dessa visão dos trabalhadores e empresários do grupo 2, pode-se explicar alguns manejos pobres em BEA encontrados nas visitas às granjas. Embora existissem e tivessem sido manifestadas nas entrevistas boas intenções para com o bem-estar das aves, a precariedade das instalações, o baixo poder de investimento e o desconhecimento dos impactos que as deficiências em sanidade, nutrição e ambiência têm sobre o BEA influenciaram negativamente os animais.

Nenhum dos agentes manifestou dificuldade quanto ao cumprimento dos requisitos para BEA contidos na norma de produção orgânica, mas as críticas feitas ao espaçamento exigido na área de pastejo foram unânimes ( $3 \mathrm{~m}^{2}$, quando não há rodízio de pastagem). Alegou-se que as aves não utilizam toda a área disponível e que se poderia então colocar mais animais por $\mathrm{m}^{2}$. Esta postura corrobora a impressão de que falta embasamento técnico a alguns manejos, pois pesquisadores como Guelber (2005) e Fanatico (2007) consideram que a composição da pastagem em termos de forrageiras, sombreamento, características de umidade e insolação do local e o rodízio das áreas tenha grande impacto sobre a nutrição dos solos e pastos, bem como sobre a sanidade das aves.
Observou-se pelos relatos das entrevistas que a debicagem é um aspecto controverso. Há tanto aceitação, por considerar-se este manejo como segurança para evitar o surgimento de canibalismo, como a condenação deste tipo de manejo, entendendo-o como uma mutilação dolorosa aos animais e que interfere com a sua capacidade de apreensão e seleção dos alimentos, atividade esta fundamental em regime de pastejo.

A granja 4 tem seus animais debicados, pois não dispõe de fornecedor de aves recriadas, que não sejam debicadas; a granja 7 entrou com pedido, junto à certificadora, solicitando permissão para debicagem, alegando ser ela uma garantia de bem-estar para o lote todo - que poderia vir a sofrer pelos desvios de comportamento de algumas aves. No entanto, constatou-se que as granjas com um manejo adequado não manifestam a necessidade de debicar os seus animais, ou mesmo relatam que, após ajustes de manejo - nutrição, porcentagem adequada de galos, controle de fontes de estresse sonoro ao redor das granjas -, o problema de bicagem de penas e canibalismo desapareceu. Em termos científicos, estudos como os de Gentle et al. (1990), Cheng (2005), Kuenzel (2007) e Marchant-Forde et al. (2008) relatam a injúria e a dor devidas ao procedimento da debicagem, considerando que podem ser de curto prazo se o procedimento for realizado nas aves com até uma semana de vida, sendo retirado menos que $50 \%$ do bico. Assim, instituições como a Farm Animal Welfare Council (2007) e a RNZSPCA (2011), embora reconheçam o impacto de tal procedimento à integridade física da ave e ao exercício de seu comportamento natural e identifiquem fatores de manejo que predispõem ao canibalismo, como intensidade de luz, seleção genética e nutrição, permitem a debicagem; considerando que os danos causados por um eventual surto de canibalismo sejam mais danosos ao bem-estar do lote como um todo. Já a American Veterinary Medical Association (2010) considera, assim como constatado em algumas granjas, que a atenção e a adequação dos fatores de manejo, juntamente com o incremento de pesquisas visando à seleção genética de linhagens com menor tendência ao canibalismo, sejam suficientes para o controle de bicagem de penas e canibalismo.

Quanto aos gargalos da produção, as entrevistas evidenciam que, por conseguirem realizar compras de insumos em escala maior, empresários do grupo 1 
conseguem suplantar as dificuldades relatadas pelos empresários do grupo 2. As principais dificuldades apresentadas por estes últimos foram: a dependência de poucos fornecedores (por exemplo, milho e soja são comprados de um único fornecedor do Paraná, distante $1.000 \mathrm{~km}$ da sua região); a dificuldade de encontrar soja não transgênica; a falta de garantia de regularidade no fornecimento de aves recriadas; a falta de fornecimento de animais sem debicagem; os custos elevados e a dependência da escala de fretes em função do pequeno volume de compra. Ambas as categorias citam ainda haver carência de tecnologia para enfrentar com facilidade e segurança os desafios surgidos durante o processo produtivo.

No grupo 1, os problemas sanitários ou de manejo são mais facilmente controlados, em função da infraestrutura e dos equipamentos disponíveis - galpões com altura de pé direito satisfatória, ventiladores e aspersores, que possibilitam a adequada regulação térmica à capacidade de compra de insumos -, além da disponibilidade de assistência técnica.

Ainda no grupo 1, os maiores gargalos residem nas restrições da norma de produção orgânica, por exemplo, ao uso de metionina sintética e a alguns adsorventes de micotoxinas em grãos (a Câmara Temática da Agricultura Orgânica, em dezembro de 2013, fez uma detalhada revisão da Instrução Normativa (IN) n ${ }^{\circ} 46$, de 6 de outubro de 2011, e flexibilizou o uso destes produtos, sem estabelecimento de prazos, até que haja possibilidade técnica da adequação da cadeia produtiva de orgânicos).

As granjas do grupo 2 relatam forte carência em termos de assistência técnica e alegam não haver disponibilidade de recursos para sua contratação. Além disso, os órgãos públicos e de extensão, que poderiam prestar tal assistência gratuitamente, lamentavelmente, apesar dos novos treinamentos e capacitações de profissionais para esse setor da economia rural, ainda não foram absorvidos pelas instituições públicas do Estado de São Paulo; portanto, a CATI (Coordenadoria de Assistência Técnica Integral) ainda não dispõe da quantidade suficiente de profissionais com formação na área de produção orgânica e de agroecologia. Nessas granjas, constatou-se que não foram seguidos procedimentos básicos de biossegurança, tais como o controle de acesso e o uso de algumas vacinas, como contra salmonela, que poderiam ter sido efetuadas caso houvesse orientação técnica adequada (Maia et al. 2011).

Esta lacuna técnica é bastante preocupante, à medida que torna os animais vulneráveis e o processo produtivo com um todo desencadeia processos de risco ao consumidor, principalmente com relação as bactérias das espécies Salmonela typhimurium e Salmonela enteritidis (Panneta, 1999).

A limitação de recursos impede também, segundo os entrevistados do grupo 2, que aspectos ligados às questões de ambiência (altas temperaturas no interior dos galpões) possam ser adequadamente manejados devido à baixa altura das construções, à falta de controle de temperaturas, à inexistência de ventiladores e a cortinas em más condições.

Na maioria das granjas visitadas, havia carência de treinamento e informações específicas sobre BEA. Os técnicos dos grupos 1 e 2 têm este conhecimento, mas os trabalhadores de granjas e os pequenos empresários rurais, em sua maioria, ainda não.

\subsection{Resultado da avaliação das condições de BEA nas granjas}

Os resultados das avaliações de BEA nas granjas estão discriminados na Tabela 2. Considerando a classificação proposta, apenas uma granja apresentou condições regulares de BEA, enquanto nas demais as condições foram satisfatórias, principalmente nas granjas do grupo 1, nas quais os requisitos maiores tiveram um cumprimento de praticamente $100 \%$. Neste grupo, apenas as granjas que optam pela debicagem não atingiram os $100 \%$, embora suas condições de manejo fossem satisfatórias, de maneira geral. Conforme salientado, as granjas do grupo 2 (com índices de 65\% a 90\%) apresentaram não cumprimentos relativos à infraestrutura, como baixo pé direito do aviário, falta de equipamento para controle e adequação da temperatura do galpão, saídas pequenas para solários, poucos poleiros e ninhos, bem como deficiências no manejo de roedores e no manejo das pastagens.

Em termos sanitários, não houve relato de qualquer surto ou mortalidade por doenças infecciosas, estando a mortalidade dentro dos parâmetros considerados normais, de $1 \%$ ao mês (RNZSPCA, 2011), em todos os 


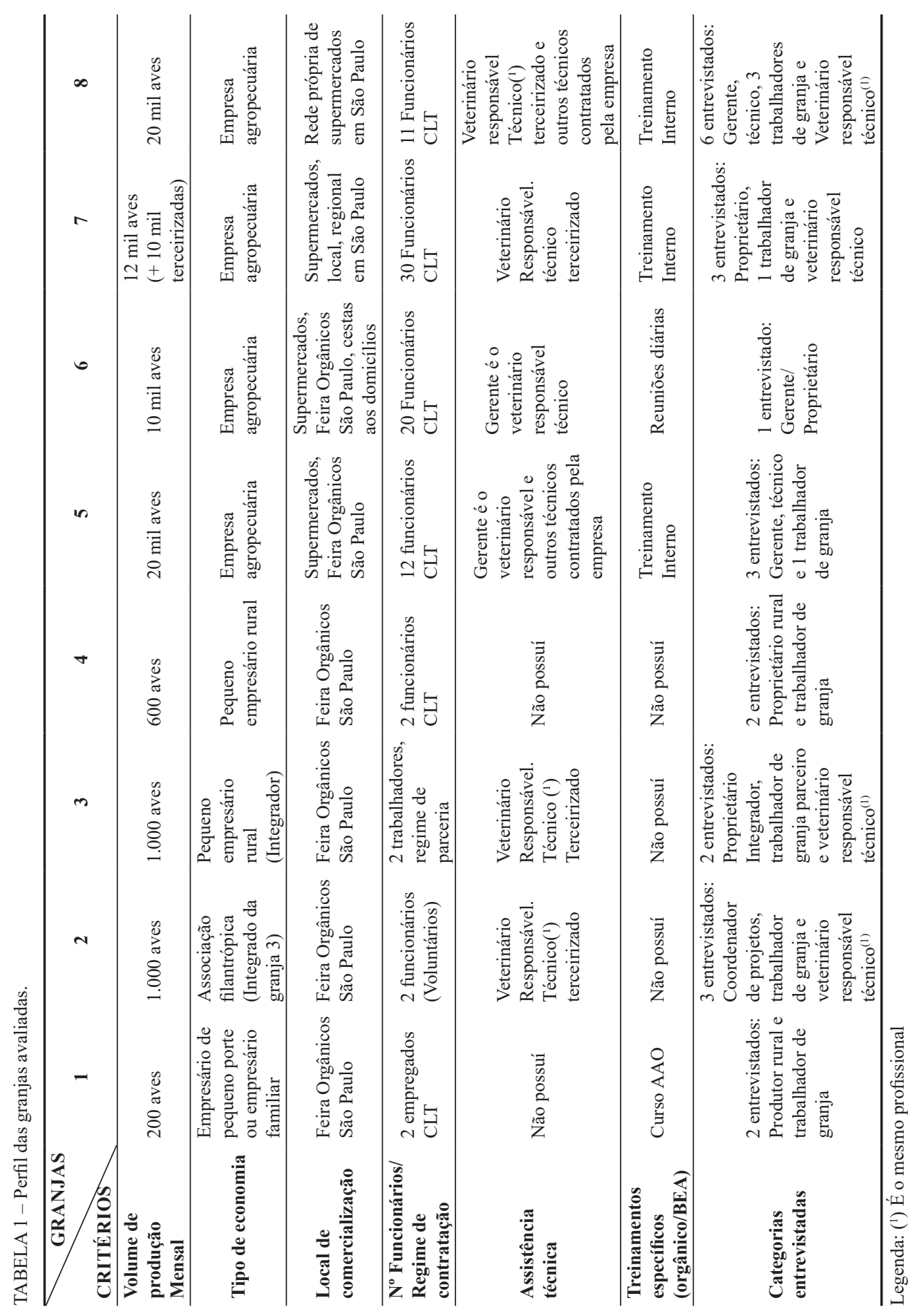




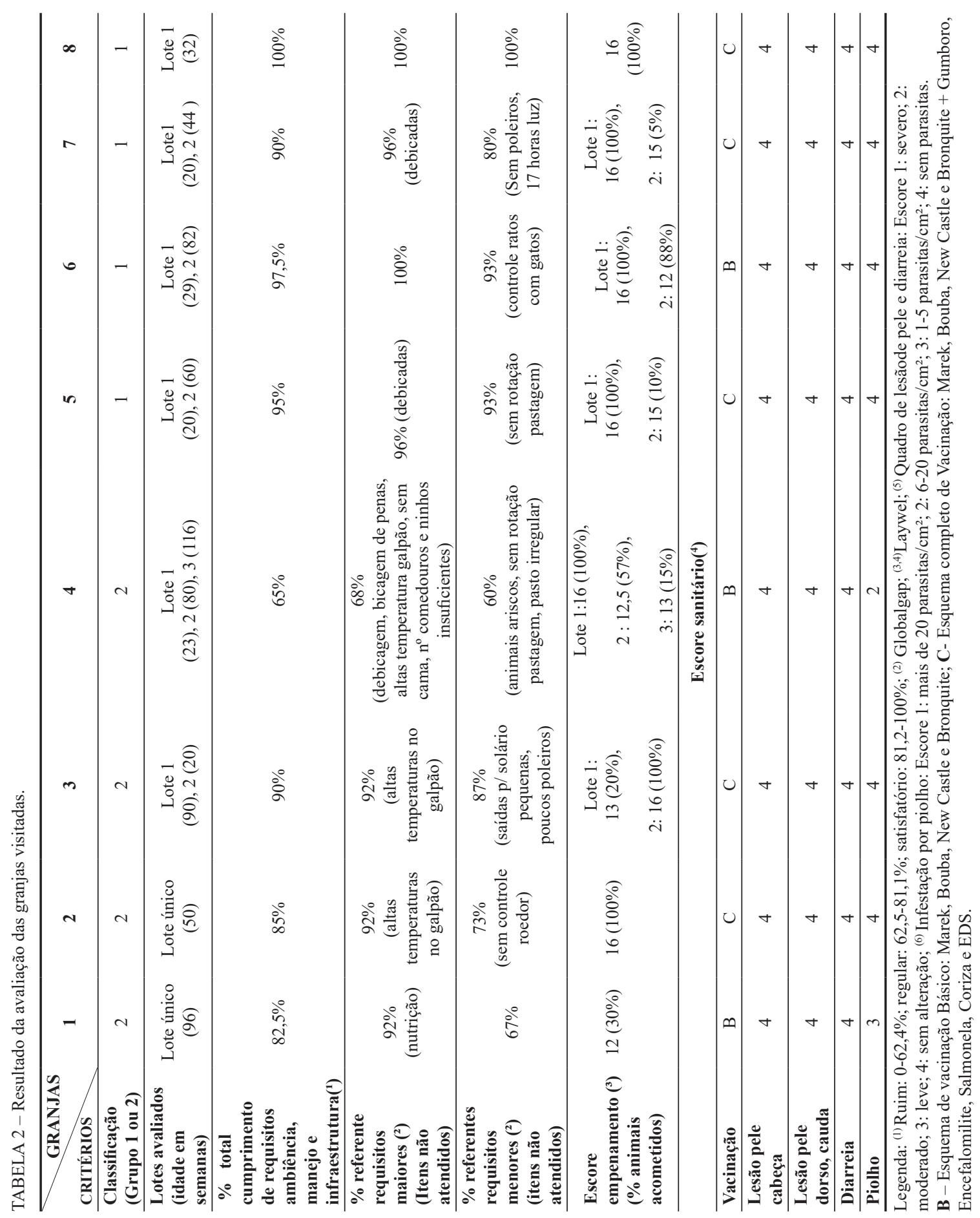


lotes visitados. Foram relatados apenas infestação por piolhos (granjas 1 e 4, controlados com óleo de citronela, (Cymbopogon winterianu) e neem (Azadirachta indica) e problemas com verminose e coccidiose, que foram controlados com fitoterapia (Artemisia vulgaris e Allium sativum) e homeopatia (granjas 7 e 8 do grupo 1). Na granja 4 do grupo 2, o composto homeopático foi retirado da ração por questões de custo. Embora a sorologia para doenças como salmonelose não tenha sido incluída nesta pesquisa, a pequena abrangência dos protocolos de vacinação das granjas menores do grupo 2 evidencia a premência da estruturação de protocolos sanitários e de biossegurança voltados às produções de pequena escala.

Quanto ao comportamento das aves, à exceção da granja 4, todos os lotes avaliados apresentaram tranquilidade e reação favorável à aproximação. Considerou-se particularmente significativa essa reação, pois, como pessoa estranha ao ambiente e à rotina das aves, a pesquisadora poderia causar-lhes algum tipo de estresse e medo, mas isso não foi evidenciado em momento algum. As aves, inclusive, acompanhavam a pesquisadora por todo seu trajeto na granja e bicavam seus sapatos quando esta parava. Apenas na granja 4, embora não demonstrassem reações imediatas de fuga diante da presença da pesquisadora, os animais fugiam assustados frente à tentativa de maior aproximação (classificados como animais ariscos, ver a Tabela 2).

\section{Conclusão}

Quanto à percepção de BEA, em sua maioria, os agentes entrevistados não conhecem o conceito do BEA, tal qual é preconizado pelas normas atuais. $\mathrm{O}$ conhecimento ainda é fluido ou pouco preciso em todas

\section{Referências}

Abreu, L. S. de. A construção da relação social com o meio ambiente entre agricultores familiares na Mata Atlântica. Jaguariúna: Embrapa Meio Ambiente, 2006. 176 p.

Abreu, L. S. De ; Paul, K.; Pettan, K.; Rabello, F.; Mendes, S. C. Trajetória e situação atual da agricultura de base ecológica as categorias do universo social da pesquisa, mas, como foi mostrado, apresenta pequenas nuances de entendimento, especialmente entre dois polos: os da categoria empresarial e o produtor familiar, o primeiro valorizando o BEA pelo viés do mercado, o segundo mais fortemente engajado num projeto associado a comportamentos alternativos e filosofia de vida de respeito à natureza e à vida.

Isso se expressa igualmente nas suas práticas observadas na avaliação das granjas. Portanto, levando-se em consideração o período de tempo a que os animais estão expostos a determinadas condições fisiológicas, comportamentais ou ambientais, os quadros de infestações por piolho, estresse térmico, nutrição inadequada, bicagem de penas, disputas por ninhos, que, embora não fossem graves, foram recorrentes, configuram-se em impacto negativo sobre o bem-estar das aves e a sanidade dos lotes.

Concluiu-se que a consonância entre o discurso dos agentes e as práticas efetivas de BEA está diretamente associada ao conhecimento sobre BEA. Onde há deficiência neste conhecimento, mesmo diante de discursos sinceros de consideração para com os animais, não há o reconhecimento ou o dimensionamento dos impactos sobre o BEA, das deficiências sanitárias, nutricionais e de ambiência. Assim, fazem-se prementes treinamentos para que se construa, com os agentes deste setor produtivo, o conceito de BEA em toda a sua abrangência ética, sanitária e econômica. Assim, as soluções e adequações para os problemas poderão ser discutidas e implementadas sobre bases mais sólidas de conhecimento.

Este quadro fluido em relação ao BEA é fruto da falta de acesso à informação, à assistência técnica ou à inexistência de políticas públicas que ofereçam condições mais objetivas para a aplicação desta diretriz nesse setor da produção. no Brasil e no Estado de São Paulo. Cadernos de Ciência \& Tecnologia, 26(1/3), 149-178, 2009.

Alencar, M. do C. B de I.; Nääs, I. A.; Gontijo, L. A.; Salgado, D. A. Effects of labor motivation in poultry production. Revista Brasileira de Ciência Avícola, 9(4), 2007. 
AVMA - American Veterinary Medical Association. Welfare Implications of Beak Trimming, 2010. Disponível em: $<$ https:// www.avma.org/KB/Resources/Backgrounders/Pages/beak-trimming-bgnd.aspx $>$.

Boni, V.; Quaresma, S. J. Aprendendo a entrevistar: como fazer entrevistas em Ciências Sociais. Revista Eletrônica dos Pós-Graduandos em Sociologia Política da UFSC, 2[1(3)], 68-80, 2005. Disponível em: $<$ http://www.emtese.ufsc.br/3_art5.pdf $>$.

Brasil. Regulamento Técnico para os Sistemas Orgânicos de Produção Animal e Vegetal. Atos legais. Instrução Normativa 46, Diário Oficial da República Federativa do Brasil, Poder Executivo, Brasília - DF, 6 de outubro de 2011 - seção 1. Disponível em: <http://sistemasweb.agricultura.gov.br/sislegis/ action/detalhaAto.do?method=consultarLegislacaoFederal $>$.

Bright, A.; Jones, T. A.; Dawkins, M. S. A non intrusive method of assessing plumage condition in commercial flocks of laying hens. Animal Welfare, 15, 113-118, 2007.

Broom, D. A History of Animal Welfare. Science. Acta Biotheoretica, 59(2), 121-137, 2011.

CEE - Comunidade Econômica Europeia. Regulamento do Conselho da Comunidade Econômica Europeia no 834/2007, de 28 de junho de 2007. Disponível em:<http://eur-lex.europa. eu/LexUriServ/LexUriServ.do?uri=OJ:L:2007:189:0001:00 23:PT:PDF>.

Cheng, H. W. Acute and chronic pain in beak trimmed chickens. In: Glatz, P. (Ed.). Poultry Welfare Issues: Beak Trimming. UK: Nottingham University Press, 2005. p.31-49.

Dias, E. F.; Mazetto, F. A importância da paisagem na Geografia. Sociedade e Território, 26(1), 92-106, 2014.

Duncan, I. J. H. Science-based assessment of animal welfare: farm animals. Scientific and Technical Review of the Office International des Epizooties, 24(2), 483-492, 2005.

Fanatico, A. Sistemas avícolas alternativos con aceso a pastura. National Sustainable Agriculture Information Service, 2007. Disponível em: <www.attra.ncat.org/espanol/pdf/avicolas_accesso.pdf>.

FAWC - Farm Animal Welfare Council. Report on Priorities for Animal Welfare Research and Development, 1993, 3-4. Disponível em: <http://www.fawc.org.uk/pdf/old/animal-welfare-priorities-report-may1993.pdf>.

FAWC - Farm Animal Welfare Council. Opinion on Beak Trimming of Laying Hens. Nov. 2007. Disponível em: <http:// www.fawc.org.uk/pdf/beak-trimming.pdf>.
Gentle, M. J.; Waddington, D.; Hunter, L. N.; Jones, R. B. Behavioural evidence for persistent pain following partial beak amputation in chickens. Applied Animal Behaviour Science, 27, 149-157, 1990.

Geoff, H.; Vicky, M. Human-animal interactions, relationships and bonds: a review and analysis of the literature. International Journal of Comparative Psychology, 27(1), 117-142, 2014.

Globalgap. General Regulations Integrated Farm Assurance: Part I, General Information. (Version 4.0-1 Fev. 2012) p. 19. Disponível em: <http://www.globalgap.org $>$. Acesso em: 15 nov. 2012.

Guelber, S. M. N. Criação de galinhas em sistemas agroecológicos. Vitória, ES: Incaper, 2005. 284p.

Hemsworth, P. H.; Coleman G.J.; Barnetta, J.L.; Jones, R.B. Jones. Behavioural responses to humans and the productivity of commercial broiler chickens. Applied Animal Behaviour Science, 41(1-2), 101-114, 1994.

IFOAM - International Federation of Organic Agriculture Movements. Basic Standards for Organic Production and Processing: version 2005. Disponível em: <www.ifoam.org>.

Jensen, P. Transgenerational epigenetic effects on animal behavior. Progress in Biophysics and Molecular Biology, 3(113), 447-455, 2013

Kjaer, J. B. et al. Reducing stress during welfare inspection: validation of a non-intrusive version of the Laywel plumage scoring system for laying hens. British Poultry Science, 52(2), 149-154, 2011

Knierim, U. Animal welfare aspects of outdoor runs for laying hens: a review. NJAS-Wageningen Journal of Life Sciences, 54(2), 133-145, 2006.

Kuenzel, W. J. Neurobiological Basis of Sensory Perception: Welfare Implications of Beak Trimming. Poultry Science, 86(6), 1273-1282, 2007

Laywel. Manual for self assessment of welfare of laying hens on farm. University of Bristol, UK, Jan. 2006. Disponível em: <http://www.laywel.eu/web/pdf/deliverable $\% 2072 \% 20$ manual-2.pdf $>$.

Maia, T. A. C.; Ribas, J. R. L.; Moura, L. G.; Batista, M. B.; Garrido, I.; Santos, J. C. M dos. Aves de quintal reagentes a Salmonella criadas no entorno de matrizeiros no polo avícola de Feira de Santana, Bahia. 2011. Disponível em: <http:// www.sovergs.com.br/site/38conbravet/resumos/611.pdfs.

Marchant-Forde, R. M.; Fahey, A. G.; Cheng, H. W. Comparative effects of infrared and one-third hot-blade trimming 
on beak topography, behavior, and growth. Poultry Science, 87(8), 1474-1483, 2008. Disponível em: <http://ps.fass.org/ content/87/8/1474.full>.

Panneta, J. C. Segurança alimentar e HACCP na produção de ovos. In: Anais do Congresso de Produção e Consumo de Ovos, São Paulo, 1999. São Paulo: APA, 1999. p. 71-78.

Rahmann, G. Why do humans keep animals? Does the answer help to define the standards for organic animal husbandry? In: $1^{\text {st }}$ SAFO-workshop "Socio-Economic Aspects of Animal Health and Food Safety in Organic Farming Systems". Florence, September, 2003. p. 5-7. Disponível em: <http://orgprints. org/8744/1/099_SAFO_Florence.pdf $>$.

RNZSPCA - The Royal New Zealand Society for the Prevention of Cruelty to Animals. Welfare standards for free range layer hens. 2011. Disponível em: <http://rnzspca.org.nz/ bluetick/blue-tick-standards $>$.
SEBRAE - Serviço Brasileiro de Apoio às Micro e Pequenas Empresas. Cartilha de Acesso ao PRONAF. Brasília/DF, 2011. p. 8. Disponível em: <http://www.biblioteca.sebrae.com.br/ bds/bds.nsf/F8D5FB4FAB4789938325771C0068DA07/\$Fi le/NT00044052.pdf $>$.

Tauson, R.; Kjaer J.; Maria G. A.; Cepero, R.; Holm, K. E. Applied scoring of integument and health in laying hens. In: European Symposium on Poultry Welfare, 7, jun. 2005, Lublin, Poland. Animal Science Papers and Reports, 23, 153-159.

Welfare Quality ${ }^{\circledR}$. Welfare Quality ${ }^{\circledR}$ assessment protocol for poultry (broilers, laying hens). Welfare Quality ${ }^{\circledR}$ Consortium, Lalystad, Netherlands. 2009.

Zeltner, E.; Helen, H. Factors involved in the improvement of the use of hen runs. Applied Animal Behaviour Science, 114, 395-408, 2008. 